\title{
El gasconismo: surgimiento de una cultura política regional*
}

\author{
Carlos Rafael Rea Rodríguez
}

En el presente artículo se analiza una cultura política regional de izquierda: el gasconismo en Nayarit (en alusión a Alejandro Gascón Mercado, figura emblemática de la izquierda de este estado de México durante cerca de tres décadas). Esta cultura política se convirtió, gracias a la exitosa e influyente gestión del Partido Popular Socialista al mando del XXVI Ayuntamiento de Tepic (1972-1975), en una matriz simbólica que alimentó la constitución de las identidades políticas de izquierda no sólo entre los miembros del partido político en que surgió, sino también entre amplias franjas de la población del municipio y del estado. Así, en un segundo momento del análisis, se estudiarán los componentes y las operaciones de la configuración identitaria a la que la cultura gasconista dio vida.

PALABRAS CLAVE: cultura política, identidad política, gasconismo

\section{Gasconism:The Emergence of a Regional Political Culture}

This paper analyzes a leftist regional political culture: the Gasconism in Nayarit (in reference to Alejandro Gascón Mercado, an emblematic figure of the left in that Mexican state for nearly three decades).Thanks to the succesful and influential administration of the XXVI Municipal Government of Tepic (1972-1975) by the Partido Popular Socialista, this political culture became a symbolic matrix that nurtured the formation of leftist political identities not only within party members, but also among broad population segments at the municipal and state levels. On a second phase of the analysis, this paper studies the components and operations of the identity formation process spawned by the gasconist culture.

KEY WORDS: political culture, political identity, gasconism 


\section{INTRODUCCIÓN}

E n el presente artículo presentaré las características centrales de lo que denomino la matriz gasconista de cultura política, y exploraré la forma como se tradujo su accionar en el proceso de constitución de identidades políticas partidistas en el estado de Nayarit. Concentraré mi atención, para la consecución de los objetivos señalados, en el periodo de auge del gasconismo (1972-1975), en el que se insertan dos fenómenos cruciales: la gestión pepesista ${ }^{1}$ del XXVI Ayuntamiento de Tepic y el fraude electoral de 1975.

Antes de hablar propiamente de culturas e identidades políticas de izquierda en esa entidad, es pertinente realizar un breve recorrido por el conjunto del sistema político nayarita, lo que permitirá comprender la constitución de las formaciones simbólicas de mi interés dentro del contexto de un complejo entramado que organiza el universo de posibilidades para su emergencia, desarrollo y declinación.

\section{EL SISTEMA POLÍTICO NAYARITA ${ }^{2}$}

Siguiendo la tesis central del ensayo de Luis Martín Sánchez Iñiguez (1996), la historia del Nayarit de las cinco décadas recientes puede entenderse como el tránsito del cacicazgo de Gilberto Flores Muñoz al cacicazgo de Emilio M. González Parra. Retomando a Sánchez Iñiguez, habré de entender operativamente al cacicazgo ${ }^{3}$ como un proceso histórico, de naturaleza social y política, en el que se observan los siguientes rasgos: 1) la hegemonía que ejerce el cacique no está sujeta a procesos electorales; 2) ejerce una función compensatoria ante los vacíos institucionales en el procesamiento de conflictos y de problemas de representación social y política; 3 ) desempeña

\footnotetext{
${ }^{1}$ Alusivo al Partido Popular Socialista (PPS).

${ }^{2}$ Este apartado del artículo ha sido presentado dentro de un ensayo en el libro Nayarit al final del milenio, coordinado por Lourdes Pacheco y Enedina Heredia (véase Rea, 1998).

${ }^{3}$ Para profundizar en la discusión respecto de este tema, véanse, por ejemplo: Paré, 1975; Wayne, 1972; y Castillo, 1983.
}

el papel de cohesionador entre el poder local y el central; 4) es un mediador político que no requiere necesariamente estar investido de representación formal alguna; 5) genera un poder que no es afectado esencialmente por la circulación intraélite; y 6) su legitimidad deriva de su intervención cotidiana, y no de procesos electivos.

Para orientar el análisis argumento que en el sistema político local son detectables, en ese periodo, tres grandes horizontes temporales: a) el de la consolidación y auge de la hegemonía floresmuñocista (1946-1963); b) el de la crisis floresmuñocista y de la transición al cacicazgo emilista4 (1963-1981), y c) el de la consolidación y auge de la hegemonía emilista (1981-1997). El periodo que estudiaré en este capítulo se inserta, por tanto, en la crisis del floresmuñocismo y en la transición al cacicazgo emilista.

El floresmuñocismo se caracterizó fundamentalmente por ser un cacicazgo sumamente violento, represivo, supresor de la disidencia social y política. Este rasgo tendió a conformar poco a poco el caldo de cultivo ideal para que emergieran las que Camou (1992: 56) denomina condiciones negativas o desencadenantes para el cambio en el sistema político vigente; esto es, fuertes déficits de gobernabilidad y la construcción de un enemigo común. Por una parte, la prácticamente nula institucionalización de la competencia y el conflicto interélites, interpartidista e interclasista dificultaban al cacique Gilberto Flores $\mathrm{Mu}-$ ñoz la preservación de su capacidad para adoptar oportunamente decisiones que fueran a la vez efectivas, aceptadas socialmente y consistentes en el tiempo ${ }^{5}$. Por otra

\footnotetext{
${ }^{4}$ Hay que advertir que este análisis no comprende los más recientes cambios al interior del sistema político nayarita, sobrevenidos a raíz de fenómenos como la muerte de Emilio González, el intenso desprestigio del saliente gobernador Rigoberto Ochoa Zaragoza (19931999), la renuncia de Antonio Echevarría a las filas del prí́smo local y la creación de la alianza opositora que, con él a la cabeza, conquistó la gubernatura del estado, así como la mayoría en el Congreso local en 1999. En esta alianza participaron el Partido de la Revolución Democrática, el Partido Acción Nacional, el Partido del Trabajo y el Partido de la Revolución Socialista local. Por supuesto, un elemento más que no está comprendido en el trabajo - y sobre el que, sin duda, hay que reflexionar para evitar interpretaciones simplistas - es el aplastante triunfo del prísmo nayarita en las elecciones federales de 2000 en las que conquistaron todas las diputaciones federales y las senadurías de mayoría.

${ }^{5}$ Estos son criterios con los que Flisfisch aborda el problema de la gobernabilidad (1989: 113-114).
} 


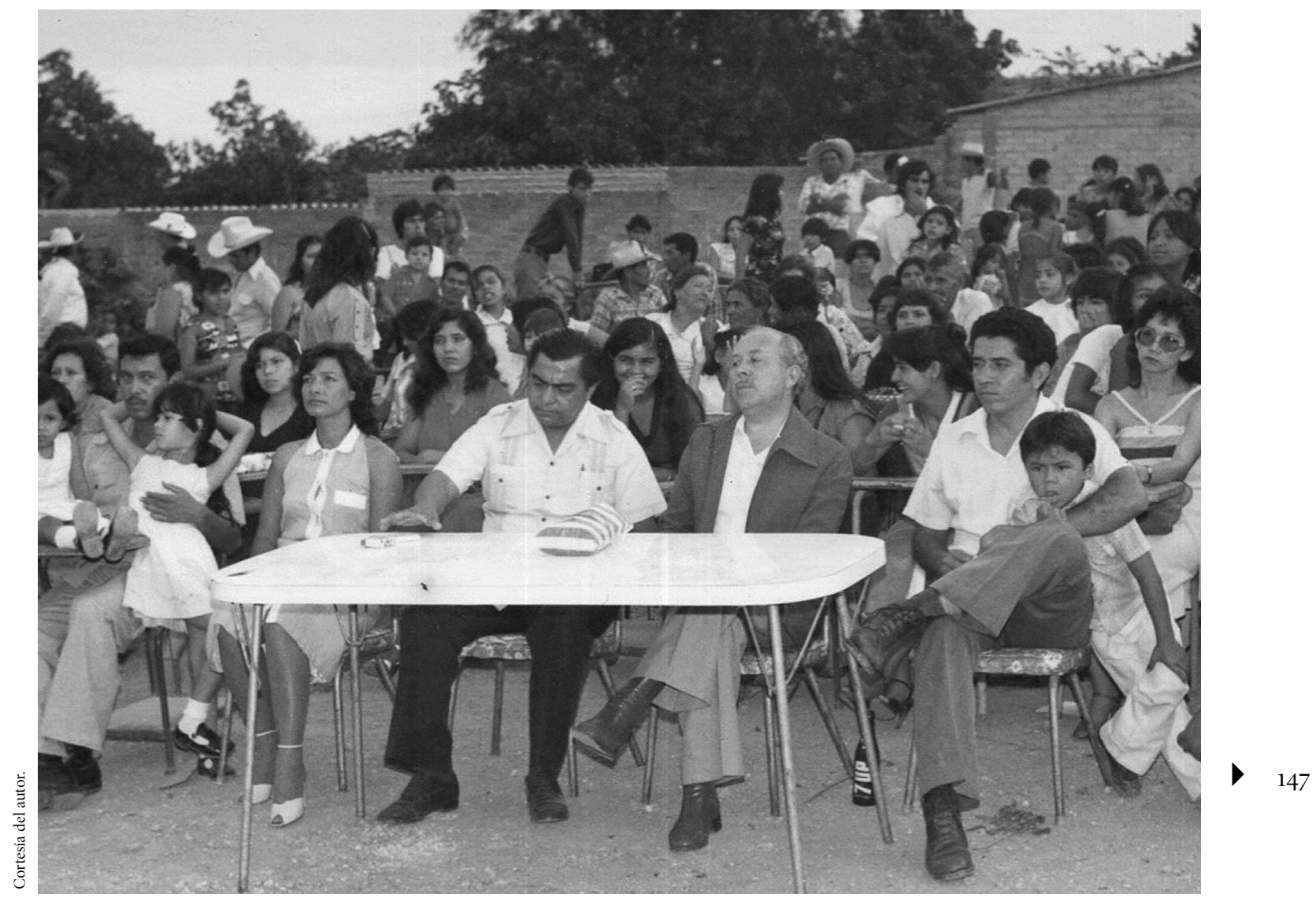

De izquierda a derecha, los dirigentes gasconistas: Raúl Rea Carvajal, José Dolores Mártir, Manuel Stephens García y José Manuel Páez.

parte, su accionar autoritario y permanentemente represivo propiciaba que fuera identificado por muchos de sus opositores como un adversario merecedor de una fuerte estigmatización moral.

La crisis de este cacicazgo ${ }^{6}$ está asociada directamente a dos acontecimientos: el fracaso de Gilberto Flores en su intento por obtener la nominación prísta como candidato a la presidencia de la República, y la designación

\footnotetext{
${ }^{6}$ Encontramos algunos indicios de la ruptura de la hegemonía absoluta del cacicazgo en la llegada de Manuel Stephens al Congreso de la Unión en 1961, y en el triunfo — no reconocido oficialmente- de José Santos González Gallo en Tuxpan, en el año de 1963. Otro hecho relevante fue el movimiento cooperativista de Bellavista (1961-1963) en el que los obreros recuperaron el control de la fábrica textil allí instalada.
}

de Julián Gascón Mercado como candidato tricolor a la gubernatura de la entidad por parte de Adolfo López Mateos. A partir de este último suceso, las bases de sustentación del poder transexenal floresmuñocista se vieron seriamente deterioradas.

Con la llegada de Julián Gascón Mercado a la gubernatura (1963-1969) se presentó el desplazamiento de la figura de Gilberto Flores Muñoz como protagonista político principal en la entidad, y con ello, también, el remplazo de su grupo por integrantes de un equipo nucleado desde el centro del país. De esta forma, la configuración de la comunidad política empezó a experimentar fuertes cambios que anunciaban la caída del cacicazgo.

En el intento de socavar el floresmuñocismo, el gobierno de Julián Gascón impulsó en el nivel del régimen 
jurídico la reactivación y culminación del reparto de tierras con base en la aplicación de la Ley de Tierras Ociosas vigente en Nayarit desde 1926 (Pacheco, 1990: 94), lo que afectó directamente las estructuras del poder económico y de control sociopolítico del cacicazgo.

Mientras tanto, las formas de regulación del conflicto registraron un viraje temporal pero significativo. Se trataba ya no del uso arbitrario del aparato estatal por parte del cacique en contra de la oposición, sino de la alianza del nuevo ejecutivo local con fuerzas sociales y políticas antes perseguidas y ahora reconocidas como interlocutores legítimos para enfrentar la dominación floresmuñocista. Consecuentemente aumentaron los márgenes de negociación entre los actores, lo que estimuló coyunturalmente la emergencia de una nueva lógica de acción política entre gobierno y oposición. Esta nueva configuración de conflictividad y correlación de fuerzas resultante permitió el auge de la movilización social y política opositora, al grado de que ésta llegó incluso a incidir significativamente en las contiendas electorales ${ }^{7}$. Así, a la par de la ponderación de la competencia electoral y al ampaversario estatal, la oposición se vio estimulada, y con ello, robustecida la pluralidad de actores dentro del sistema.

Sin embargo, la campaña de desprestigio en contra del "gobernador comunista" - encabezada por los representantes de los capitales trasnacionales cervecero y tabacalero instalados en Nayarit - no se hizo esperar, y este naciente grupo político no logró consolidarse. Su naufragio definitivo tomó forma claramente con el arribo de Roberto Gómez Reyes, su sucesor en la gubernatura (1969-1975), quien decidió apoyarse para su gestión en los grupos económicos y políticos locales anteriormente hegemónicos (Pacheco, 1990: 49).

A contramano de la postura de Julián Gascón, Gómez Reyes llevó a cabo medidas tales como declarar la inexistencia de tierras para repartir (Pacheco, 1990: 54) como

\footnotetext{
${ }^{7}$ Lo anterior se tradujo en el arribo de Alejandro Gascón Mercado, por primera vez, al Congreso de la Unión, y en la campaña del doctor Fausto Luque (destacado miembro del PRI local) como candidato a la presidencia municipal de Tepic por el PPS en 1969, candidatura que sirvió de antecedente directo del triunfo solferino en 1972.
}

recurso para proteger los latifundios agrarios que aún persistían, sobre todo el de Flores Muñoz. Otra de las características importantes de su gobierno fue la permanente obstaculización al Ayuntamiento pepesista de Tepic (1972-1975), cuyo titular era precisamente Alejandro Gascón, hermano de su antecesor en la gubernatura.

Con Roberto Gómez Reyes cambiaron nuevamente los grupos depositarios de la autoridad gubernamental y se presentaron iniciativas legales que afectaban regresivamente al régimen. Sin embargo, debido a las tendencias observadas en el plano de la composición de la comunidad política (auge del Partido Popular Socialista —PPSy consolidación del núcleo gasconista; y desde fuera del sistema político, la multiplicación de movimientos sociales opositores en todo el estado, así como la reactivación de instancias intermedias como ejidos, cooperativas y sindicatos), de la incipiente pero perceptible liberación de las reglas del juego (sobre todo en el plano electoral) y de los consecuentes cambios en las formas de conflictividad y las lógicas de acción, puede afirmarse que las bases del cacicazgo de Flores Muñoz se encontraban en franca declinación.

En el segundo trienio de Gómez Reyes se vive la experiencia del Ayuntamiento pepesista de Tepic. Con el inobjetado triunfo del candidato del PPS en 1972 se inaugura un momento que habría de tener repercusiones trascendentales para el sistema político estatal y aún para el nacional. El éxito de los solferinos es atribuible a tres factores: a) la solidez del grupo político dirigente conformado centralmente por Alejandro Gascón Mercado, Rafael Gómez Aguilar, Salvador Castañeda O'Connor, José Santos González Gallo, Manuel Stephens García, Sabino Hernández Téllez y Raúl Rea Carvajal; b) la inclusión estratégica en su plantilla de gobierno municipal de personajes locales del Partido Comunista Mexicano (PCM) (Severiano Ocegueda Peña) y del mismo Partido Revolucionario Institucional (PRI) (Germán Goldman), y, particularmente, c) a la creación de los Comités de Campaña (después erigidos en Comités del Pueblo).

No obstante la animadversión de que fue objeto por parte del gobierno del estado, el XXVI Ayuntamiento de Tepic pudo introducir variaciones importantes en el sistema político local. En primer término destaca el hecho 
de que la alianza de varios actores políticos y sociales opositores en torno a la figura de Alejandro Gascón marcó el predominio coyuntural de una pauta de acción estratégica, en la que, más que anteponer sus perfiles doctrinarios, los partidos y grupos convergentes decidieron compartir la posibilidad de derrotar al que identificaban como el enemigo común. Esta pauta de acción llevó a priorizar coyunturalmente como lugar de disputa a la arena electoral, situación que pivotó de alguna manera la diversificación del repertorio de formas de acción de los actores involucrados, arrojando, entre otras cosas, la modalidad organizativa que con el tiempo sería su expresión más acabada: los Comités de Campaña. Esos comités, ya rebautizados por el ayuntamiento pepesista en gestiones como Comités del Pueblo — junto con los entonces creados Comandos del Pueblo-, representaron un notable aporte organizativo al ejercicio ciudadano dentro de la gestión municipal. De hecho, puede sostenerse que gracias a la estructura de los Comités del Pueblo, durante ese periodo se vivió en Tepic un inusitado aumento de la participación social por vías completamente institucionales.

En lo que respecta al régimen, el titular del XXVI Ayuntamiento consiguió que se reconociera como una posibilidad, a nivel federal, que la base de sustentación económica del municipio fuera el impuesto predial. A escala local, pese a no haber consolidado jurídicamente la figura de los Comités del Pueblo, los pepesistas tuvieron muchos logros notables 8 : consiguieron la apertura pública de las sesiones de la Cámara de Diputados, de la calificación de diputados y regidores por el Colegio Electoral, así como de la comparecencia de funcionarios estatales y federales. Con medidas como éstas fue posible disminuir de manera considerable la permanente distancia entre el accionar del gobierno y de los políticos respecto de la ciudadanía.

Puede decirse que la repercusión de la gestión pepesista en Tepic fue de alcances inusitados. Prueba de ello es que, al proponer instancias y medidas de gobierno in-

\footnotetext{
${ }^{8}$ Gracias en gran medida a la presencia del PPS en el Congreso local,
} a través de la labor de su diputado Raúl Rea Carvajal. novadoras, los herederos de Lombardo Toledano fueron capaces de vapulear la hasta entonces inalterable hegemonía priísta, poniendo en entredicho el patrón de legitimidad que le había dado sustento. Por esa razón, la experiencia socialista de Tepic atrajo los ojos interesados de grupos nacionales y extranjeros, pero también la mirada preocupada de las élites gobernantes en el país. Para no permitir una onda expansiva de esta experiencia local, el sistema político nacional hizo sentir su preeminencia. Con el fraude electoral de 1975 se cerró uno de los capítulos más aleccionadores en la historia del sistema político local.

Paradójicamente, el fraude en Nayarit ${ }^{9}$ ocurre justo cuando en el país estaba por concluir el periodo (19461976) que Peschard denomina de construcción y consolidación hegemónica del sistema de partido hegemónico (Peschard, 1993: 101-106), para dar paso a otro que llama de hegemonía en un marco de liberalización política (1977-1986), caracterizado por una serie de reformas tendientes a mitigar el monopolio estatal priísta ${ }^{10}$.

En clara asincronía respecto de estas tendencias federales, Nayarit vivió un momento de claro endurecimiento reestabilizador del sistema local. Una vez impuesto fraudulentamente el coronel Rogelio Flores Curiel en la gubernatura del estado (1975-1981), se desencadenaron procesos que revirtieron de manera profunda los atisbos de democratización que venían ocurriendo.

En los años previos al fraude se vivía la crisis de la hegemonía floresmuñocista; sin embargo, el cacicazgo no era sustituido por ninguna nueva configuración de dominación. Al mismo tiempo, tendencias democratizadoras, que anunciaban nuevas formas de regulación del conflicto mediante la institucionalización de la competencia electoral, presionaban desde fuera y dentro al sistema político local. Este escenario encontró su punto de inflexión

\footnotetext{
${ }^{9}$ Sobre este particular véase Pacheco (1990) y Rea (1993).

${ }^{10}$ Algunas de esas reformas son la incorporación en la Ley Federal de Organizaciones Políticas y Procesos Electorales (LFOPPE) del registro condicionado; el traslado de la decisión del otorgamiento del registro a los partidos de la Secretaría de Gobernación a la Comisión Federal Electoral; la reglamentación del acceso de los partidos a los medios de comunicación y del apoyo oficial a sus campañas; la introducción de la representación proporcional, etcétera (Peschard, 1993: 10).
} 
justo en 1975, año en que, con la imposición del gobernador militar, se empalmaron la crisis de la hegemonía floresmuñocista y la de la legitimidad del sistema mismo. Como consecuencia de este doble fenómeno se criticó ya no sólo el para quién se gobierna, sino también la forma de tener acceso al gobierno. El sistema reprobó su examen de democracia al sobrevenir el fraude. Sin embargo, la crisis de legitimidad del régimen no rebasó nunca el umbral mínimo para la preservación del control social, y el reequilibramiento fue posible mediante la represión subsecuente.

Tendríamos que decir que durante este periodo los cambios registrados fueron de naturaleza intrasistémica (de varios de sus componentes, según Morlino, 1985). Si bien hubo la posibilidad de impulsar cambios integrales que sentaran las bases para procesos de liberación política que generaran un juego institucionalizado de contrapesos políticos, esta tendencia fue finalmente revertida. El temor del Estado mexicano a permitir la complejización funcional y la autonomización del sistema político en Nayarit se expresó en la refortificación del gubernaturismo local a como diera lugar.

\section{LA CULTURA POLÍTICA GASCONISTA ${ }^{11}$}

Dentro del contexto rápidamente expuesto se amalgamaba el gasconismo, cultura política de un grupo que alcanzó su esplendor precisamente en el periodo 1972-1975.

Como ya quedó asentado en la introducción, por cultura política entiendo, en términos generales, aquellas articulaciones de sentido que definen formas colectivas concretas de concebir y actuar lo político. Para el caso particular de la cultura política gasconista, es posible adentrarse en ella estableciendo los enclaves o nodos que articulan, de manera más o menos coherente, la intersección de las distintas formaciones discursivas preexistentes que

${ }^{11}$ Para desarrollar este punto revisé los periódicos Diario del Pacífico (1972 y 1975) y Vida Nueva (1975), y llevé a cabo entrevistas de historia oral a José Santos González Gallo, Salvador Castañeda O'Connor y Raúl Rea Carvajal. le dieron vida, a saber: los principios básicos de la doctrina marxista-leninista (en su versión estalinista), el ideario nacionalista-antiimperialista del lombardismo, y el imaginario local-nacional de lucha agrarista. La configuración de cultura específica que resulta de esta articulación no se reduce a ser una mera expresión de una cultura política global (parroquial, cívica o democrática, a la manera de Almond y Verba, 1963), o una cultura política de izquierda homogénea, sea nacional o local.

Se trata, en cambio, de la cultura política de un grupo partidista de izquierda local que se constituyó por múltiples elementos simbólicos provenientes del contexto internacional y nacional (incluidas otras culturas políticas), pero que estuvo fuertemente condicionada por las especificidades ya expuestas del entorno sistémico de la entidad (particularmente por la presencia del cacicazgo de Gilberto Flores Muñoz), y aun por los perfiles identitarios de los protagonistas de la experiencia del XXVI Ayuntamiento de Tepic. En este último sentido hay que destacar dos situaciones interesantes que aparecen como constantes en la biografía de varios de los cuadros dirigentes gasconistas: 1) su desprendimiento del seno familiar desde temprana edad (González Gallo, Gascón Mercado, Rea Carvajal, Castañeda O'Connor), y 2) la participación política dentro de las filas del magisterio nayarita (Stephens García, González Gallo, Rea Carvajal, Hernández Téllez). Estos dos factores incidieron en la conformación del equipo gasconista, proporcionando un espacio de adscripción que operó como sustituto de la familia y que repercutió decisivamente en los altos grados de solidaridad y lealtad generados entre sus miembros; y en segunda instancia, dotándoles de un piso más o menos común de valores y prácticas con los que se incorporaron a la formación de este núcleo político.

Históricamente, es a partir del triunfo electoral de 1972 que el grupo político encabezado por Alejandro Gascón tuvo la oportunidad de poner a prueba sus maneras de concebir y actuar la política. De hecho, fue ésta la ocasión propicia para fortificar sus posiciones políticas, traducir sus intenciones en programa y cristalizar orgánicamente sus vínculos con otros partidos y con la población. En ese momento se fraguaba un grupo político que con los años llegó a proyectarse nacionalmente gracias a que po- 
seía fuertes rasgos culturales e identitarios que le distinguían de los de otros contingentes políticos.

Debido a la conquista simultánea de importantes posiciones en cargos de elección popular ${ }^{12}$, la perspectiva gasconista y su estilo de hacer política se consolidaron poco a poco como la formación discursiva que llegó a ser la más significativa dentro de la izquierda en el estado ${ }^{13}$; esto es, la cultura política hegemónica. Esta hegemonía se tradujo en la capacidad de los dirigentes gasconistas para articular a otros contingentes gracias a que supieron asumir e incrementar las coincidencias existentes con ellos - especialmente con personajes del PCM, el Partido Auténtico de la Revolución Mexicana (PARM) y el PRI-, y en razón también de que instituyeron como propias muchas de las demandas populares más sentidas en ese momento, incorporándolas a su discurso y estimulando con ello el fenómeno de identificación de la población con el gasconismo.

Otra de las razones principales del auge de esta cultura política fue el severo cambio en la percepción de los grupos gobernantes hacia la dirigencia pepesista, los cuales, de mostrar un claro menosprecio hacia la capacidad política del accionar gasconista, pasaron a considerar a este equipo como el adversario principal a combatir.

En síntesis, las nociones y actuaciones gasconistas ejercieron una especie de colonización de los circuitos por los que fluía la comunicación política, llegando a permear de manera tal a otros sectores dentro y fuera del sistema político que desbordaron incluso a sus mismos gestores. Con la autonomización de esta emergente cultura política, su condición hegemónica se consolidó, a la vez que crecía su posibilidad de perpetuación como matriz simbólica de referencia de identidades colectivas de posterior emergencia. Es a partir de este momento de la exposición que intentaré demostrarlo.

\footnotetext{
${ }^{12}$ Como fue el caso de la diputación federal para Salvador Castañeda, la diputación local para Raúl Rea, al mismo tiempo que la presidencia municipal para Alejandro Gascón.

${ }^{13}$ Otras culturas políticas importantes con las que competía el gasconismo fueron la sostenida por los miembros del Partido Comunista Mexicano en la entidad y la que protagonizaban grupos de orientación de masas en el municipio de Tuxpan, quienes obtuvieron la presidencia de ese municipio en 1972 con el registro del Partido Auténtico de la Revolución Mexicana.
}

Conviene ahora desarrollar las características principales de esta cultura política. Para ello se requiere tener una visión integral que desentrañe su lógica básica y que dé cuenta de sus puntos nodales y de sus contradicciones más relevantes.

Para entender el auge gasconista hay que señalar que su legitimación se llevó a cabo por medio de una doble operación discursiva: en primera instancia, conformando paulatinamente una memoria colectiva anclada en la referencia a los intereses y valores encarnados en las demandas y símbolos de la Revolución mexicana y el cardenismo; en segunda, "futurizando" y condensando esos intereses y valores en una utopía con perspectiva escatológica ${ }^{14}$. De esa manera, Zapata, Villa, Madero, Cárdenas y Lombardo Toledano emergen como los emblemas que atestiguan el presente desde el pasado, mientras que Marx, Engels y Lenin son los voceros del juicio histórico de una abstracta humanidad futura.

En la convergencia de estos referentes legitimatorios se entretejía un cuerpo de valores, intereses, actitudes, saberes, sentimientos, anticipaciones, esperas y proyecciones que, no obstante sus contradicciones y mutaciones constantes, lograron fijar enclaves desde los que se obtenía la suficiente coherencia para operar como marco cognitivo y configurador de la acción. Retomando la distinción entre lo integrativo y lo instrumental, propondré enseguida cuáles son desde mi perspectiva los puntos nodales que articulan este universo.

\section{La dimensión integrativa del gasconismo}

Son ocho los elementos distintivos que operaban como ejes estructurantes del gasconismo: cuatro en el terreno integrativo y cuatro más en el instrumental. En primera instancia, y como rasgo que permea a los demás nodos integrativos (el leitmotiv), destaca la fuerte imbri-

\footnotetext{
${ }^{14}$ Reconozco la utopía no como el pretendido destino ineluctable de un proyecto político, sino como horizonte movilizador de expectativas que se reconoce a la vez como un no lugar (a la manera de Claude Léfort). La utopía escatológica remite a un horizonte futuro que se vislumbra como necesidad histórica ineluctable.
} 


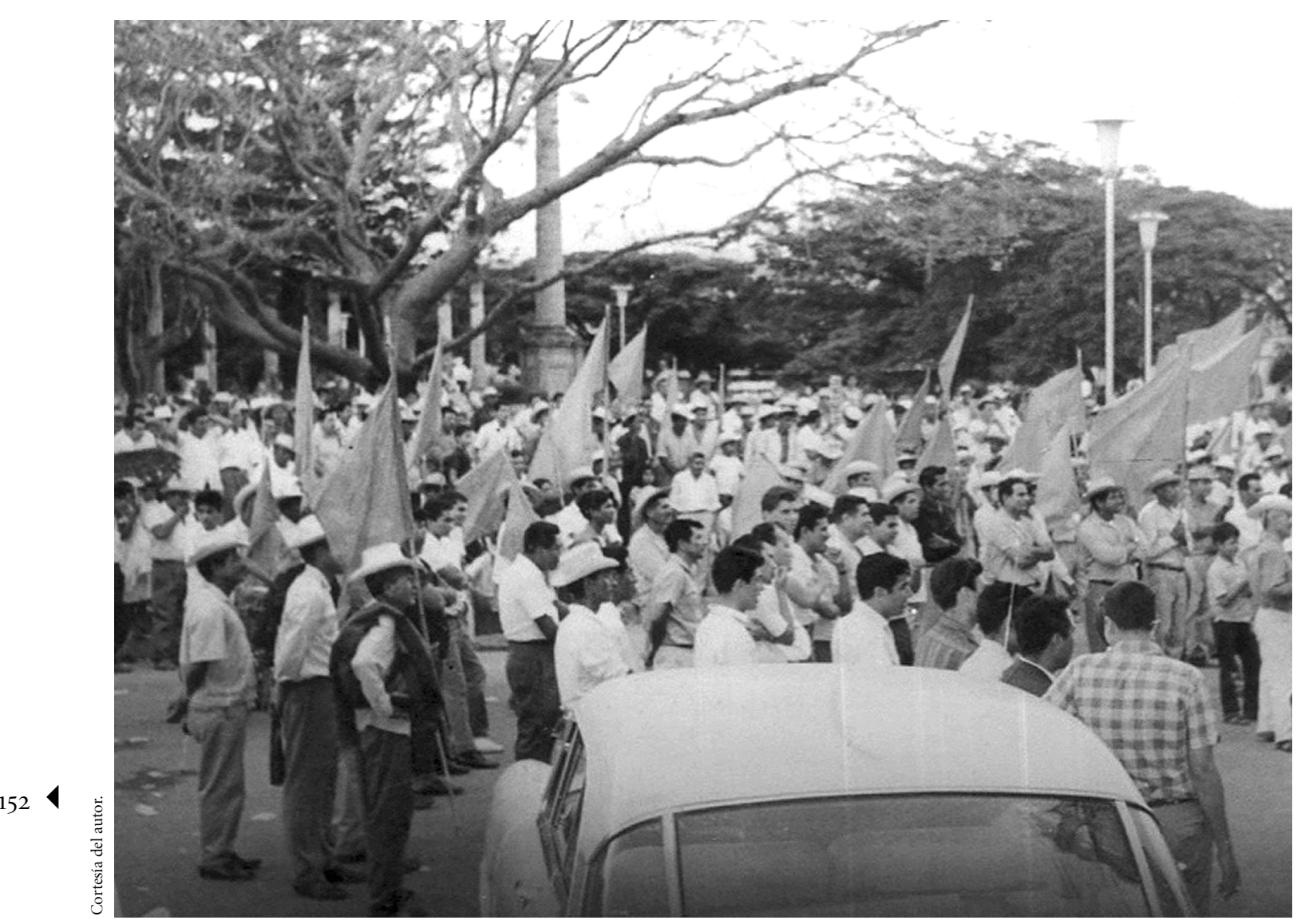

Mitin del PPS en la plaza principal de Tepic.

cación de los códigos de lo moral y lo político; de hecho, puede incluso decirse que hay una supeditación de la racionalidad política a las consideraciones de orden moral. Es así que los momentos de toma de decisiones más importantes ante los que se encontró el equipo gasconista fueron resueltos no por un cálculo que ofreciera ventajas o avances estratégicos o tácticos ante un adversario público, sino por una dura defensa de los valores morales característicos de su constitución identitaria. Como ejemplo paradigmático de lo dicho está la declaración de Alejandro Gascón ante la propuesta hecha por el vocero gubernamental, Porfirio Muñoz Ledo ${ }^{15}$, para dar salida al

${ }^{15}$ El ofrecimiento gubernamental era: a cambio del reconocimiento conflicto electoral de 1975: "antes que posiciones de orden político, salvaguardar el honor de nuestro pueblo". En este caso, Gascón Mercado planteó alternativamente la realización de un nuevo proceso electoral, aún con el riesgo de perderlo todo.

Un segundo elemento nodal es la postura sacrificial que asumen los protagonistas del gasconismo, quienes dentro de la dinámica festiva de la lucha política ofrecían

pepesista del triunfo de Rogelio Flores Curiel, se otorgaba a este partido la Secretaría General de Gobierno, la mitad de las presidencias municipales y la mitad menos uno de las diputaciones locales, así como la postulación para los siguientes comicios de Alejandro Gascón como candidato a senador por el PRI y el PPS, al igual que la de algún pepesista por designar para la diputación federal. 
ritualmente la subsunción de su condición de privados (con sus dinámicas, derechos y obligaciones) a la construcción de un nosotros público-político que pugnaba revolucionariamente por la redención universal.

Resultan ilustrativos los términos con los que, sobre este punto, se expresan González Gallo ${ }^{16}$ y Rea Carvajal ${ }^{17}$. El primero recuerda con orgullo el momento en que decidió comunicar a su familia que "se jubilaba como padre" para dedicarse completamente "al servicio de sus ideas", situación que le implicó mudarse a vivir solo a partir de ese instante. El segundo, por su parte, al hacer un ordenamiento jerarquizado de sus prioridades vitales en aquel periodo, coloca en primera instancia el fortalecimiento de las posiciones políticas que defendía, posteriormente el bienestar de su familia, y sólo al final la propia condición personal.

La consecuencia directa de la postura sacrificial era la obligación que se imponían los actores de ser un ejemplo en el cumplimiento de las tareas político-partidarias y en la observancia de los valores estructurantes del sentido colectivo. Esta ejemplariedad se extiende a todos aquellos ámbitos privados que son expuestos al juicio público, pero que suelen no penetrar necesariamente al ámbito íntimo de sus vidas, particularmente en lo referido a la igualdad genérica dentro del contexto familiar.

Desprendido del anterior factor, encontramos como cuarto rasgo la tendencia a un vanguardismo político de naturaleza moral y práctica (ascética), más que ideológica. Amalgamando el imaginario apostolar descrito (que tiene por núcleo duro la decisión personal voluntaria) y una ideología política teleológica (que predestina roles políticos a cumplir y desenlaces históricos), la mayoría de los miembros del grupo gasconista asumía que para lograr la emancipación popular se requería de la dirección de quienes entendían y actuaban los designios de la historia.

Sin embargo, para ellos la condición de vanguardia era, en los hechos, un papel a conquistar. Fue a partir de la necesidad que Vicente Lombardo Toledano les había in-

\footnotetext{
${ }^{16}$ Entrevista realizada por el autor en enero de 1998, en Tepic, Nayarit. ${ }^{17}$ Entrevista realizada por el autor en noviembre de 1997, en Tepic, Nayarit.
}

culcado de vincularse estrechamente con las luchas sociales como premisa de la organización popular que estos cuadros políticos rigieron su desempeño por tantos años, llegando a encabezar algunas de las luchas más significativas en Nayarit durante la década de $1960^{18}$. Los pepesistas eran, pues, dirigentes políticos no por su conocimiento de la teoría socialista, sino porque diversos grupos y sectores sociales y políticos los reconocían como tales. Narrativamente, lo anterior era expuesto por los propios protagonistas bajo el argumento de que el liderazgo social era una consecuencia natural de su práctica y no un objetivo a conseguir. Alejandro Gascón llegó a declarar, por ejemplo, exhaltando el vínculo que le unía a los nayaritas, que "para poder ser su dirigente necesito ser perseguido como el pueblo", así como ser también pobre por convicción.

La premisa del vínculo partido-pueblo era también el parámetro de referencia para caracterizar a otros contingentes. Así, por ejemplo, de los miembros del Partido Comunista Mexicano (que no aceptaban ningún tipo de contacto con el gobierno) opinaban sin ambages que eran sectarios y que no poseían arraigo popular en razón de su escaso contacto con luchas concretas de la población.

Desentrañemos ahora lo medular de la narrativa ideológica y de la acción ritual del gasconismo. La ideología marxista-leninista establece que las leyes que rigen el desarrollo de la humanidad revelan que su destino está supeditado a la actuación revolucionaria de las grandes masas populares, que tienen invariablemente por motor al proletariado, clase social que requiere de una vanguardia política revolucionaria que le dote de una dirección científica, a la que por sí misma no puede arribar. En correspondencia con estos preceptos ideológicos, el gasconismo es la sublimación (hipostasiación) de las proyecciones de la colectividad que le dan vida, sublimación por medio de la cual estas últimas se presentan narrati-

\footnotetext{
${ }^{18}$ Así lo ilustran los casos de la lucha obrera en la fábrica textil de Bellavista (1961-1963), el movimiento contra el cacicazgo floresmuñocista para lograr la venta de tabaco a Checoslovaquia, y la creación de la Unión de Pescadores Libres, con 57 secciones que incorporaron a más de 5000 miembros a lo largo de la costa del estado (Rea, 1993).
} 
vamente como los anhelos, en última instancia, de la humanidad entera. Así, los intereses del partido son los intereses históricos del proletariado, que son los mismos del pueblo y, por ende, de la humanidad toda. De esta forma, el partido no hace otra cosa que personificar por derecho y como una entidad especializada los intereses históricos de la especie humana.

Debido a lo formidable e inconmensurable de esta autoimpuesta responsabilidad histórica, el precio que había que pagar por tomar este camino imponía a los postulantes un sacrificio igualmente inconmensurable. De ahí que, para pertenecer a este equipo o para dirigirlo, era necesario renunciar prácticamente a la idea del interés personal como derecho legítimo.

Junto con la ponderación de ciertos valores que servían de cemento al grupo (la fraternidad, la solidaridad y la lealtad) y que posibilitaban que la dinámica colectiva estuviera caracterizada por la permanente discusión y toma de decisiones en conjunto y por consenso, y como consecuencia de la autonegación personal como condición para la afirmación en la colectividad, se verificaba narrativa del conflicto al interior del grupo. Por medio de este mecanismo las concepciones diferentes a las hegemónicas eran subsumidas voluntariamente en la orientación marcada por el dirigente máximo: Alejandro Gascón. De esa manera, a pesar de la existencia, durante la gestión del XXVI Ayuntamiento, de opiniones diversas a las del dirigente (como las que solían tener José Santos González y Raúl Rea), y aún de inconformidades y conflictos dentro del equipo pepesista (lo cual evidenciaba la crisis del liderazgo absoluto que hasta entonces había prevalecido), Alejandro Gascón siguió como el reducto decisional finalmente reconocido y acatado por el grupo ${ }^{19}$.

${ }^{19}$ Por ejemplo, sobre la postura asumida en 1975 de no negociar con el gobierno federal, Rea recuerda que Gascón Mercado impuso el criterio, pero que los demás lo compartieron completamente (entrevista citada).

\section{La dimensión instrumental del gasconismo}

En el nivel de lo instrumental se perciben características notablemente avanzadas. Los primeros dos ejes detectados aquí son la interesante dosis de pragmatismo y el programa democrático-popular que el gasconismo heredó del ideario lombardista. El programa gasconista contemplaba que, debido a las circunstancias histórico-concretas que se vivían entonces en el concierto internacional y en los contextos nacional y local, era posible aspirar a un tránsito pacífico hacia el socialismo. El cambio social así concebido sería posible al avanzar en la consolidación de las potencialidades de la democracia burguesa, para desde ahí transitar por una vía menos traumática que la violenta a la construcción del socialismo.

A partir de esta concepción general se estructuró un programa político que planteaba el apego a la vía legal en la lucha por la democracia. Esta defensa de la legalidad tenía que ver, entre otras cosas, con el pertrechamiento contra nuevos episodios represivos como los de 1968 y 1971 en México, y contra desenlaces de corte fascista en el país, como el ocurrido por esos años en Chile.

En esta lógica de lucha democrática se amalgamaban posiciones en primera instancia antiimperialistas; en segunda, anticapitalistas y socialistas. Por lo tanto, y sin renunciar a la autopercepción como vanguardia, los gasconistas se imponían la necesidad de forjar alianzas electorales no sólo con otros grupos políticos socialistas o comunistas, sino también con organizaciones opositoras de otro signo, y aún con sectores del partido oficial y de la misma burguesía, siempre y cuando abrigaran o coincidieran con demandas nacionalistas, antiimperialistas o antifascistas, o con proyectos concretos que apuntaran en sentido del bienestar del pueblo. Esta flexibilidad llegó a propiciar situaciones extremas como la confianza en que el gobierno echeverrista, congruente con la apertura política que había llevado a cabo hasta entonces en el país, y en razón de su orientación antifascista y pretendidamente nacionalista en política internacional, decidiría respetar el resultado de las elecciones en Nayarit, fuera cual fuera. Por supuesto, esto jamás ocurrió así.

Junto con la preferencia por la vía democrática se encontraba el énfasis en el ingrediente popular (ese tercero 
discursivamente interpelado como testigo, juez, aliado y actor), que permeaba poderosamente la concepción y la actuación instrumental gasconistas. Acorde con todo el planteamiento ideológico ya esbozado en el que partido-clase-pueblo y especie humana se tornaban equivalentes, el programa gasconista reivindicó insistentemente no sólo el derecho del pueblo a ser representado, sino además a ser protagonista directo de la vida política. Esto encontró su cristalización máxima durante la gestión del XXVI Ayuntamiento de Tepic en la creación de los Comités ${ }^{20}$ y los Comandos del Pueblo, así como en la realización de los informes públicos mensuales que rendía el edil pepesista ante la ciudadanía en la plaza principal.

De manera particular, en la práctica ritual de los informes públicos convergían una dimensión expresiva nodal y una pretensión claramente estratégica. A la vez que buscaban ser congruentes con la concepción en la cual el pueblo es la fuente de toda soberanía, el que avala, vigila y sanciona el ejercicio del poder público, los pepesistas también entendían cabalmente que la escenificación de la política como espectáculo plebiscitario aseguraba instrumentalmente la ampliación de sus clientelas y la proyección de sus dirigentes.

En otro sentido, las estrategias retóricas convertidas en narrativas programáticas se fincaban de manera subyacente en un encadenamiento distinto a la "sublimación" expuesta para el caso de lo integrativo. Si en el caso previo se trataba de la condición históricamente preestablecida de vanguardia, éste otro tenía que ver con la capacidad de interpretar correctamente, en el terreno de los hechos, las demandas humanas, populares y de clase. Si en el primer caso ocurría una trasposición simbólica que hacía de los intereses partidarios la expresión "por naturaleza" de los intereses de la humanidad, en este úl-

\footnotetext{
${ }^{20}$ Los Comités del Pueblo fueron órganos de gestión vecinal electos a través de voto universal directo y secreto a convocatoria del Ayuntamiento de Nayarit. Los rubros que de manera reglamentada conocían eran: obras públicas, tesorería, educación, deportes y vigilancia. Por su parte, los Comandos del Pueblo estaban conformados por policías auxiliares voluntarios elegidos en sus localidades por voto secreto (Rea, 1993: 66-69).
}

timo sucede una suerte de suplantación práctica. A este fenómeno podemos denominarle "efecto de oráculo" (Pierre Bourdieu, 1996).

La metáfora del oráculo es el mecanismo por medio del cual se deposita la autoridad discursiva en el representante. El partido habla por la clase, por el pueblo y por la especie; el partido ordena discursivamente el mundo pasado, presente y futuro; traza las estrategias y las tácticas, y toma las decisiones. A los "legítimamente representados" les corresponde brindar apoyo, a partir de aceptar la ficción de que la decisión tomada por el partido es auténticamente suya: la dirigencia habla en nombre de los dirigidos y los dirigidos asumen que lo dicho por ella es en realidad lo que su voz quisiera expresar. Correlativamente, el partido asume la ficción de interpretar a cabalidad, con su opinión y decisiones, los anhelos del proletariado-pueblo-humanidad.

En el caso concreto del gasconismo este fenómeno se manifiesta en un doble y contradictorio discurso. Por un lado, los gasconistas hablaban a través del "nosotros" (lo siguen haciendo en las actuales narrativas individuales), en consonancia con la propuesta de que la voz decisoria emanaba del colectivo; sin embargo, claramente funcionaba, en sentido inverso a esta premisa, el que es el tercer eje instrumental del gasconismo, es decir, el culto colectivo e individual a la personalidad de Alejandro Gascón (alimentado por él mismo), que hacía que el oráculo no fuera la dirección pepesista, sino su dirigente máximo en la entidad, en quien se sintetizaban — desde su percepción-las características intelectuales, morales y prácticas más elevadas, necesarias para dotar de dirección a todo un pueblo. Quizá la razón de esa mitificación radicara en el hecho de considerársele como el heredero legítimo de Vicente Lombardo Toledano, de quien por algunos años Alejandro Gascón fue secretario particular.

Existen opiniones sobre el Alejandro Gascón de inicios de la década de 1960 como un hombre lúcido, intuitivo, brillante, líder indiscutible, valiente, claro, sencillo, con gran calidad humana y arraigo social, que fungía políticamente como catalizador, pararrayos, punta de lanza y oráculo (según Raúl Rea). Algunos más lo consideraban como el jefe indiscutible, fraterno, celoso del cumplimiento de las tareas y exigente, y como un gran forma- 
dor de cuadros ("a veces llenándolos demasiado de virtudes”, según Salvador Castañeda).

Sin embargo, quienes fueron desde entonces los más activos críticos del dirigente máximo desde el interior del propio grupo gasconista, opinan hoy ${ }^{21}$ que es a partir de la gestión del XXVI Ayuntamiento que aquél empieza a mostrar importantes deformaciones. José Santos González narra que, al hacerse esquemático en lo político y al pasar por encima de los parámetros doctrinarios legados por Lombardo Toledano, Alejandro Gascón "se erosionó ideológicamente" y acabó sobredimensionando su papel dirigente, desprendiéndose en su práctica de la estructura partidista ${ }^{22}$. Raúl Rea, por su parte, añade que la condición humana de Alejandro Gascón devino egoísta, prepotente y políticamente paranoica respecto de opiniones distintas a la suya o de personalidades con aureola propia.

Lo cierto es que Alejandro Gascón logró hacer prevalecer su perspectiva política en todo momento, mostrando de manera elocuente su capacidad personal para usar estratégicamente su papel dentro de la configuración identitaria del grupo, así como su habilidad para mantener, en primera o en última instancia, sus decisiones estratégicas, y en muchos casos tácticas.

En otra dirección encontramos, como cuarto eje articulador de la dimensión instrumental de la cultura gasconista, la triada de acciones concretas que dotaban de eficacia y capacidad de reproducción a las estrategias narrativas gasconistas expuestas hasta aquí: la vinculación plebiscitaria con la gente en las plazas públicas, el contacto personalizado con los seguidores de su causa en

\footnotetext{
${ }^{21}$ Es importante establecer que Raúl Rea Carvajal rompió con el grupo gasconista debido a la discusión ideológica en torno a la perestroika soviética, con la que el primero coincidía plenamente. José Santos González Gallo, por su parte, se confrontó con Alejandro Gascón en 1997, impulsó exitosamente la expulsión de este último de las filas del Partido de la Revolución Socialista (PRS) local, a pesar de ser Gascón el dirigente moral de este organismo a nivel nacional.

22 Quizás el aludido fenómeno de sobrestimación encuentre un correlato condensado en algunas de las expresiones de la campaña de Gascón en 1975: cuando hacía referencia al interpelar al pueblo de Nayarit a "el papel de conductor que me han dado"; al asegurar también que conseguiría erradicar el analfabetismo del estado en un año "porque Fidel lo hizo en Cuba"; y cuando prometía igualmente que él no traicionaría la decisión popular como lo hicieron Almazán y Henríquez Guzmán.
}

el ámbito íntimo de su vida cotidiana, y el efectivo respeto a la orientación que la gente imprimía a su propio accionar político por las vías institucionales (particularmente en los casos de los comités y los comandos del pueblo).

La construcción de credibilidad, confianza y consenso se basó, entonces, en el culto a la figura y la actuación de Alejandro Gascón y, contradictoriamente, en la interpelación a la vez pública e íntima del pueblo por parte del líder y su equipo, y en el respeto a las iniciativas populares. De esta dualidad emanaban en los hechos la debilidad y la fortaleza máximas del gasconismo: la supeditación de las decisiones, en última instancia, en un solo hombre, y el involucramiento identitario y práctico en el programa pepesista de amplias franjas de la población.

En síntesis, la cultura política gasconista se caracterizó en su momento de esplendor por: 1) la defensa ideológica del paradigma revolucionario (de corte estalinista); 2) la postura sacrificial de sus dirigentes; 3 ) la imbricación insistente entre los códigos de lo moral y lo político; 4) la asunción de un papel de vanguardia moral; 5) un accionar pragmático eficaz hacia los otros actores políticos no antagonistas; 6) un programa de corte democrático-popular; 7) la existencia del culto a la personalidad de su líder con base en el efecto de oráculo, y 8 ) la consecución de lealtades sociales con base en un accionar a la vez plebiscitario y personalizado.

Con contradicciones internas importantes y mutaciones casi imperceptibles o fuertes y evidentes, el gasconismo logró operar como un marco de interpretación y ordenamiento discursivo de la realidad, como una estructura configuradora de las pautas de actuación de los protagonistas y aun de aquellos a quienes interpelaban directamente, y como una instancia que otorgaba reconocimiento y legitimidad, o indiferencia y hasta estigmatización, a maneras concretas de concebir y actuar la política.

Históricamente, el triunfo pepesista de 1972 y la gestión del XXVI Ayuntamiento consolidaron un proceso político que llevó más de dos décadas gestar, a la vez que condensaron sus características más influyentes en el cuerpo de una cultura política que, con el tiempo, hegemonizó el horizonte opositor en la entidad. 
Sin embargo, con el fraude electoral de 1975, el gasconismo experimentó el momento de inflexión que habría de marcar su transformación definitiva y el surgimiento de su mito principal. Al quedar evidenciados los límites que imponía el sistema político federal en sus pretensiones de apertura democrática controlada, surgió claramente también el dilema central que marcó la radicalización ideológico-política del gasconismo. Ante el fraudulento desenlace del proceso electoral de 1975, en el que estaba en juego la gubernatura del estado, las conversaciones entre la dirigencia pepesista local y el gobierno federal comprendían, en primera instancia, las posiciones siguientes: el gobierno ofrecía a los gasconistas prácticamente la mitad de los cargos de elección en el estado, mientras que, por su parte, los segundos exigían la anulación del proceso y la realización de nuevas elecciones. Todo parecía indicar que una nueva contienda se llevaría a cabo. Sin embargo, repentinamente, el gobierno modificó su postura y, negociando directamente con Jorge Cruishanck García (en ese entonces dirigente nacional del Partido Popular Socialista) $-\mathrm{y}$ ya no con Alejandro Gascón Mercado-, el Ejecutivo federal logró, a través de la persona de Porfirio Muñoz Ledo, que la dirección nacional solferina reconociera el triunfo del candidato priísta, el coronel Rogelio Flores Curiel, a cambio de una candidatura al Senado de la República por el estado de Oaxaca para el propio Jorge Cruischank. La dirigencia nayarita, a pesar del insistente reclamo de muchos de sus simpatizantes para que el candidato llamara a la movilización, decidió organizar la retirada debido a la presencia de miles de militares en el estado, así como al viraje político del Ejecutivo federal. No aceptaron ningún cargo de representación, pero tampoco reconocieron al gobernador impuesto.

Conviene aquí considerar algunas de las posiciones esgrimidas por los gasconistas a lo largo de este episodio, pues en ellas se condensan muchos de los rasgos de su cultura política hasta aquí expuestos.

La plataforma política del PPS de cara al proceso electoral apelaba a la participación del pueblo en las urnas como condición para el triunfo democrático. Por esta vía habrían de llevarse a cabo medidas que, de una manera democrática y nacionalista, impulsarían el desarrollo del estado en materias de producción industrial, agrícola, pecuaria y forestal, turismo, reparto agrario, incorporación femenina al mercado de trabajo, organización del descanso de los trabajadores, etc. El llamado hecho al pueblo fue, en todo momento, reivindicando los cauces legales y la acción pacífica, principalmente debido a que estaba presente la posibilidad del violentamiento del proceso como recurso del gobierno para legitimar una salida dura; pero también en razón de la existencia de una cierta confianza en el actuar echeverrista, a la vez que un cálculo estratégico que les hacía suponer que no le era conveniente al régimen empañar el proceso aperturista nacional con la mancha del fraude en Nayarit. Este cálculo falló y el fraude sí ocurrión 23 .

En el momento del desenlace, Gascón Mercado aseveraba: "tratándose de cuestiones de principios, nosotros no estamos dispuestos a este tipo de negociaciones" (Diario del Pacifico, 27 de noviembre de 1975), y proyectaba esta idea afirmando que "nuestro pueblo no está dispuesto, en las cuestiones de principios, a renunciar al derecho elemental de designar sin violencia a sus legítimos representantes" (ibid.). Después de los conocidos resultados arrojados por la negociación, replanteaba: “¿Qué hubiéramos ganado con tener un presidente municipal, un diputado o un senador? Lo que el pueblo tiene es una gran satisfacción de que el PPS no negoció con sus intereses y sus decisiones" (Vida Nueva, 23 de enero de 1976)".

Sin embargo, la derrota política se consumó y, a pesar de que la dirección gasconista decidió "no negociar con la voluntad del pueblo", el desencanto generalizado sobrevino. Ahí abortó lo que, a decir de los pepesistas, seguramente habría marcado el inicio del cambio democrático del país entero. La emergencia del mito que en lo sucesi-

\footnotetext{
${ }^{23}$ Quisiera dejar anotada la hipótesis que José Santos González Gallo formula hoy para explicar este desenlace. Este veterano dirigente socialista sostiene que la gestión del Ayuntamiento provocó el descuido del trabajo partidista a nivel organizativo. Por eso, la dirección pepesista fue incapaz de coordinar adecuadamente las expectativas y la iniciativa popular que en todo el estado desbordó las capacidades de su estructura. A la postre esto significó una severa parálisis política, pues ante el gran riesgo de no poder imprimir la dirección y el ritmo convenientes a una posible movilización masiva de protesta contra el fraude, la dirección pepesista permaneció en la inmovilidad (entrevista citada).
} 
vo lanzaría al gasconismo a la escena nacional como una de las fuerzas protagonistas de la iniciativa unitaria que desembocaría en la creación del Partido Socialista Unificado de México (PSUM), paradójicamente vaticinaba también el socavamiento definitivo del enclave social que podía darle sustento.

Después de este crucial capítulo, el gasconismo vivió modificaciones importantes en su configuración: su postura ideológico-política se radicalizó, el tono revolucionario de su discurso se acentuó en detrimento de su optimismo democrático; las ligas con el Ejecutivo federal se deterioraron a tal grado que, de considerarlo como potencial aliado ante la cerrazón de los grupos locales de poder, pasó a asumirlo como uno más de sus oponentes. De hecho, la percepción de las relaciones de oposición se exacerbaron de tal manera que el adversario se transformó en enemigo, es decir, en un oponente al que había que suprimir.

Por último, la perspectiva teleológica se reprocesó bajo el argumento de que lo que el pueblo había hecho con la decisión tomada por los gasconistas era replegarse, posponiendo temporalmente su victoria, la que final e inevitablemente habría de llegar.

\section{LA IDENTIDAD POLÍTICA DEL GRUPO GASCONISTA}

Ya ubicado el gasconismo como la metaformación discursiva de referencia para el proceso de constitución y reproducción identitaria de algunos de los principales actores políticos en Nayarit en este periodo, me concentraré en la exposición de lo concerniente a la dimensión identitaria del equipo político gasconista. Para esto abordaré dos ejes temáticos fundamentales: los mecanismos identificatorios que le caracterizaron y el fenómeno de la lealtad en su seno.

\section{Los mecanismos de identificación/diferenciación}

De manera muy general, lo identitario remite a una operación de distinción del yo (individual o colectivo) res- pecto de los otros (individuales y/o colectivos también). Esta distinción se produce por medio de mecanismos identificatorios/diferenciadores que generan, a la vez, inclusión y exclusión; solidaridades, indiferencias y estigmatizaciones; permanencias y migraciones.

Para el caso del equipo gasconista sostengo que fueron dos los tipos de identificación en juego ${ }^{24}$. Puede hablarse de una identificación valorativa que nombraba como superior a la utopía, los principios y valores que este grupo enarbolaba por ser los que presuntamente se correspondían con los designios contenidos en las leyes generales de la sociedad. El sentimiento colectivo se integraba de esta forma por la adhesión y la lealtad a lo nombrado como superior (que era la imagen de porvenir a conquistar), suprimiendo de antemano la legitimidad de cualquier tipo de cuestionamiento hacia esta posición. Todo lo que no fuera incluido en esta percepción era, como consecuencia, estigmatizado implícitamente como inferior.

Otro de los mecanismos identificatorios/diferenciadores que operaron tenía que ver con la dicotomía general popular/no popular ${ }^{25}$. Se trataba de una manera de agrupar y distinguir intereses prácticos, consagrando positivamente todo aquello que emanara o fuera en beneficio del pueblo y estigmatizando lo que no coincidiera con ello. Encontramos expresiones retórico-narrativas de esta concepción, por ejemplo, en la permanente referencia de Gascón Mercado a su capacidad de representación auténtica debido a que proviene del seno mismo del pueblo (el 23 de enero de 1976 señala: "No llegamos ayer. Aquí nacimos, aquí gateamos, esta tierra fue la que probamos, estos terregales fueron en los que nos bañamos").

Por supuesto, no basta la distinción del yo y los otros para hablar de identidad política. Precisamente, lo dis-

\footnotetext{
${ }^{24}$ Josexto Beriain (1996) señala que son dos las "distinciones directrices" que permiten hablar del otro: las relaciones "arriba/abajo" y "adentro/afuera". Su función es determinar la inclusión/exclusión de los individuos dentro de una unidad sociocultural.

${ }^{25}$ Pueden ubicarse como dicotomías que se encuentran en el mismo nivel discursivo las oposiciones de interés nacional $v s$. imperialismo, interés popular $v s$. dominación burguesa, e incluso, dirección política revolucionaria vs. oportunismo político.
} 


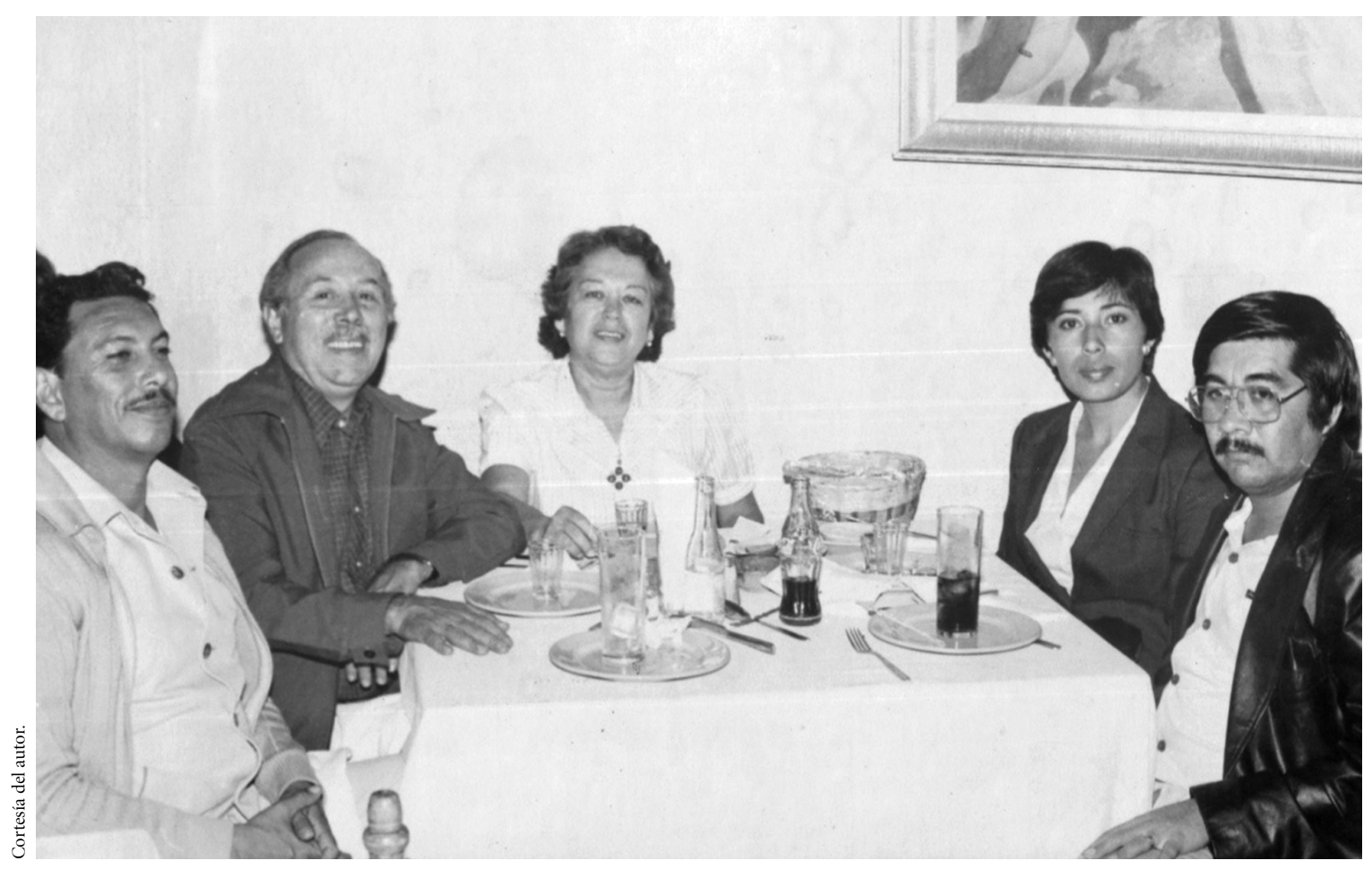

De izquierda a derecha: Raúl Rea Carvajal, Manuel Stephens García, dos mujeres no identificadas y José Manuel Páez.

tintivo de esta última queda contenido en la oposición antagónica entre dichas entidades. Es la construcción discursiva del otro como adversario público lo que politiza distintivamente a las identidades. Es así que el grupo gasconista no sólo se deslindaba de los valores que concebía como inferiores, sino que los combatía; su objetivo era diezmarlos, cuando no someterlos o suprimirlos. Es también así que los intereses que divergían de los de su concepción de pueblo eran estigmatizados y confrontados de manera abierta.

Esta distinción identitaria ocurrió no sólo a partir de las fronteras orgánicas que delineaban la existencia partidista. De hecho, para los gasconistas hubo un "afuera" doble: por un lado, lo inferior y lo no popular que quedaba en el afuera del partido, y lo inferior y lo no popular adentro mismo del partido. La pugna de los gasconistas no era exclusivamente contra el imperialismo, los cacicazgos, la burguesía y su Estado, sino además contra la propia dirigencia nacional solferina que, a decir suyo, se entrega- ba aceleradamente al control gubernamental, abandonando el legado del ya extinto Vicente Lombardo Toledano.

El conflicto contra la dirección nacional pepesista estaba matizado de manera interesante por una reticencia inicial por parte del grupo nayarita a la confrontación directa, pues existía en su concepción mística una actitud antirrupturista anclada en el reconocimiento a la condición del dirigente (lo cual puede quizás leerse como un culto a la dirección). Esta situación alcanzó su punto más álgido después de 1975, justo con la salida de los gasconistas del PPS para formar, en 1978, el Partido del Pueblo Mexicano.

\section{La lealtad}

Retomando la propuesta de Pizzorno (1989), me interesa aquí el tema de la lealtad por dos razones: 1) permite distinguir en una disposición concéntrica los tipos de pertenencia y, por tanto, de integrantes o miembros con los 


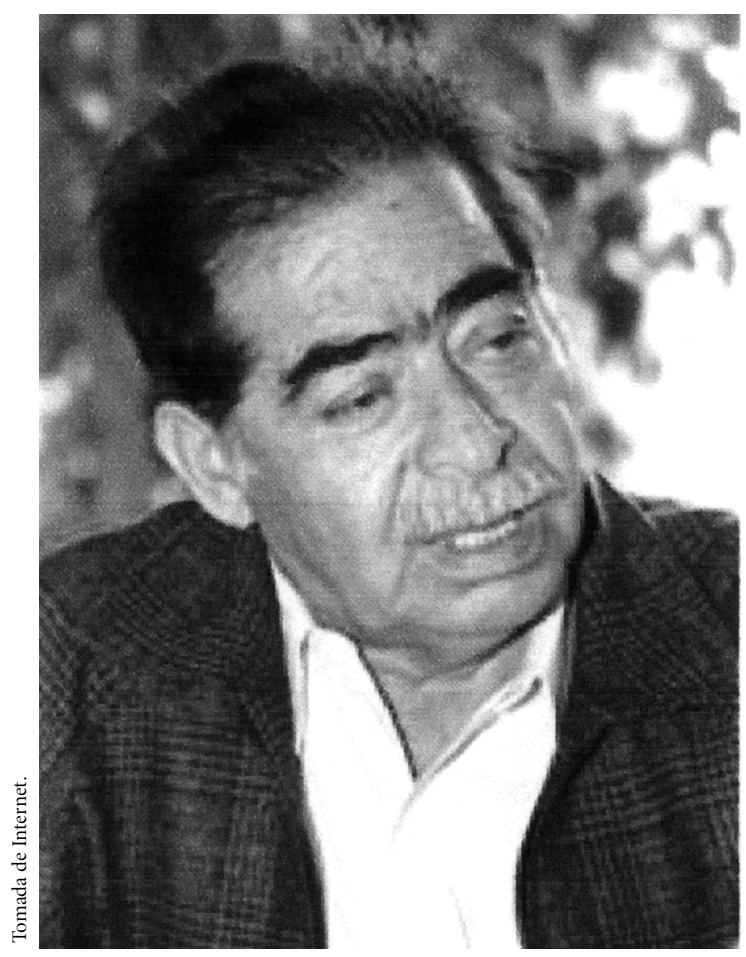

Alejandro Gascón Mercado.

que contaba el grupo gasconista, así como el tipo de interacciones que entre ellos ocurrían, y 2) llama la atención sobre las operaciones de temporalización de tales interacciones que hacían posible la permanencia en o salida del grupo.

En la experiencia del grupo gasconista se constituyeron cuatro tipos de militancia que correspondían a niveles diferentes de lealtad. En primer término, Alejandro Gascón fungía como el meta-identificador por antonomasia del grupo, como la figura emblemática en la que todos sus compañeros se veían cabalmente representados. En algún sentido, Alejandro Gascón representaba al equipo, y el equipo se condensaba simbólicamente en él.

Después venía un primer nivel de colectivización de la dirección en el que, en forma cerrada, intervenían Alejandro Gascón Mercado, Salvador Castañeda O'Connor y Manuel Stephens García. Finalmente, el grupo se ampliaba e incluía a José Santos González Gallo, Raúl Rea Carvajal, Sabino Hernández Téllez y Rafael Gómez Aguilar, principalmente. El conjunto de estos dirigentes conformaba, en definitiva, el cerebro del grupo gasconista.

El núcleo dirigente ampliado era tal porque de él surgían muchas de las decisiones que tendían a procesar las incertidumbres, a asumir los riesgos y a enarbolar emblemáticamente muchos de los valores e intereses del colectivo. Pero su capacidad dirigente emanaba también del hecho de ser el círculo de reconocimiento básico a través del cual los integrantes del pepesismo se aproximaban a Alejandro Gascón en un sentido ascendente, a la vez que porque operaba como el nivel de interpelación del conjunto de la membresía (caracterizada por una alta lealtad) y de los simpatizantes (poseedores de una baja lealtad, potenciada o difuminada coyunturalmente), en un sentido descendente. La condición reconocida de garantes, de sancionadores de una causa pretendidamente universal que así se reproducía era el motivo de lealtad de los miembros dirigentes hacia el grupo, era la razón por la cual resultaba identitariamente más conveniente permanecer integrados al equipo en lugar de salir de él, a pesar de los sacrificios que esto implicara. Puede decirse, por tal razón, que estos individuos eran todos miembros identificadores.

Sin embargo, eran Gascón, Castañeda y Stephens quienes, por la dinámica cerrada que les caracterizaba, operaban como los miembros de mayor lealtad en el colectivo. Esta cerrada célula podía existir por el reconocimiento que se les otorgaba en el nivel más amplio de la dirección. Eran los miembros más influyentes y, por tal motivo, también a quienes más costosa les resultaba la salida del grupo. Eran, en sentido estricto, los puntales de la identificación, pues su permanencia aseguraba certidumbre para el resto. Al mismo tiempo, eso significaba que una eventual salida del grupo les habría representado una severa crisis de autopercepción y autovaloración, por lo cual su permanente adhesión al grupo era fundamental, no tanto para los otros como para sí mismos.

En el nivel más elevado, Alejandro Gascón se erigía como la condensación mítica de la herencia lombardista y de la utopía emancipadora. La totalidad de los dirigentes reconocían en él un conjunto de características que lo erigían como el conductor indiscutible, no sólo por su capacidad política real, sino, en mayor medida, debido al 
efecto de una nociva sublimación del anhelo colectivo en una instancia míticamente trascendente y difícilmente expuesta al error.

El vanguardismo ideológico-político, el efecto de oráculo que alimentaba el culto a la personalidad y la sublimación del ánimo colectivo en la persona mitificada de Alejandro Gascón propiciaron que la configuración identitaria del equipo pepesista fuera muy autorreferente y cerrada. Consecuentemente, el accionar concreto del grupo se vio supeditado en momentos críticos a intereses y motivaciones que tenían que ver más con la preservación interna de los roles de influencia y adscripción (como condición estructurante de la certidumbre colectiva), que con la búsqueda de resultados políticos externos. El mecanismo de preservación identitaria descrito encontraba justificación narrativa en una idea básica: "la decisión del pueblo no se negocia", cuando en realidad lo que no se aceptaba poner en juego era la configuración identitaria que los mantenía.

Una última idea que deseo introducir tiene que ver con el tiempo. Para el equipo gasconista la configuración de los anclajes identitarios que alimentaba su autopercepción y que les permitía actuar hacia el exterior estaba supeditada a una operación evaluativa futurizada. El discurso gasconista y sus decisiones fundamentales atendían a una serie de parámetros valorativos e instrumentales que no eran asumidos directamente como propios. Antes bien, esos parámetros pertenecían a la humanidad entera y podían ser interpretados gracias al conocimiento de las leyes generales del desarrollo de la sociedad. Pero la proyección identitaria gasconista no concluía ahí. El juicio hacia el discurso político sostenido por este grupo habría de provenir de una humanidad futura; al acogerse al juicio de la historia, los gasconistas sacrificaban sus yoes individuales y colectivos presentes en aras de un yo universal futuro.

Esta “futurización", según Pizzorno, es característica de identidades colectivas que se asemejan en su funcionamiento a una secta religiosa. Para el caso del grupo gasconista es su perspectiva ideológica la que permite organizar coherentemente esta operación, estableciendo de antemano un perfil óptimo de los posibles yoes futuros y sujetando la actuación de los yoes presentes a un pro- yecto político (y de vida, en sentido amplio) orientado a la consecución de ese estado.

En síntesis, la identidad del grupo gasconista se estructuraba a partir de dos mecanismos de inclusión/exclusión: la distinción valorativa superior/inferior (representable en la dicotomía proletariado/burguesía, ) y la distinción de interés popular/no-popular. Así, los adversarios construidos discursivamente eran la burguesía, el imperialismo, el fascismo, el Estado mexicano, el cacicazgo; mientras que sus aliados eran todos aquellos que coincidieran con la lucha histórica del proletariado o con los intereses concretos del pueblo, sin importar de dónde provinieran esos contingentes. Desde luego, en razón de que los gasconistas abrigaban lo superior y lo popular, el pivote de su integración, adscripción y permanencia era la identificación y la lealtad alrededor de la idea de ser la vanguardia del cambio revolucionario en este país.

Finalmente, la estructuración identitaria del grupo se basaba en dos mecanismos principales: la mitificación de Gascón Mercado como una entidad trascendente e infalible, y la transferencia de la capacidad evaluadora del accionar del yo colectivo presente hacia un yo universal futuro.

Con el fraude electoral de 1975, la identidad gasconista se enfrentó a un momento crucial. Este acontecimiento permitió al grupo replantear la configuración identitaria que le era característica, propiciando la reestabilización de los mecanismos identificatorios y de las lealtades. Esto cristalizó principalmente en el apoyo brindado por todos los miembros de la dirección a las decisiones tomadas en esos momentos por Alejandro Gascón en el enfrentamiento contra los voceros del gobierno federal y contra el mismo dirigente nacional del PPS (meses antes, las identificaciones de algunos de los miembros de mayor lealtad en el grupo se habían visto alteradas a raíz de las diferencias que emergían respecto del comportamiento de su dirigente). Otra fuente de incertidumbre identitaria fue también la pugna contra la matriz organizativa nacional del grupo. Sin embargo, y paradójicamente, fue también este instante de crisis el que obligó a los gasconistas a cerrar filas y, con ello, a alimentar una dinámica de reproducción doblemente autorreferente que les permitió sobrevivir a tan dura experiencia política. 


\section{Bibliografía}

Almond y Verba, 1963, The Civic Culture: Political Attitudes and Democracy in Five Nations, Princeton University Press, Princeton, New Jersey.

Beriain, Josexto, 1996, "La construcción de la identidad colectiva en las sociedades modernas", en Beriain y Lanceros (comps.), Identidades culturales, Universidad de Deusto, Bilbao, pp. 13-44.

Bourdieu, Pierre, 1996, Cosas dichas, Gedisa, Barcelona.

Camou, Antonio, 1992, "Gobernabilidad y democracia”, $\mathrm{Ne}$ xos, núm. 170, febrero, México, 37 y ss.

Castillo, Héctor, 1983, La sociedad de la basura: caciquismo en la ciudad de México, Universdad Nacional Autónoma de México, México.

Flisfisch, Ángel, 1989, “Gobernabilidad y consolidación democrática: sugerencias para la discusión”, Revista Mexicana de Sociología, año LI, núm.3, julio-septiembre, Universidad Nacional Autónoma de México, México, pp. 113-133.

Morlino, Leonardo, 1985, Cómo cambian los regímenes políticos, Centro de Estudios Constitucionales, Madrid.

Pacheco Ladrón de Guevara, Lourdes, 1990, Nayarit: sociedad, economía, politica y cultura, Centro de Investigaciones Interdisciplinarias en Humanidades, Universidad Nacional Autónoma de México, México.

Paré, Luisa et al., 1975, Caciquismo y poder político en el México rural, Siglo XXI, México.
Peschard, Jacqueline, 1993, "El fin del sistema de partido hegemónico”, Revista Mexicana de Sociología, núm. 2, abriljunio, Universidad Nacional Autónoma de México, México, pp. 97-117.

Pizzorno, Alejandro, 1989, "Algunas otras clases de otredad: una crítica de las teorías de la 'elección racional", en Foxley et al. (comps.), Democracia, desarrollo y el arte de traspasar fronteras, Fondo de Cultura Económica, México, pp. 369-387.

Rea, Carlos, 1993, Sociedad civil y movimientos sociales. La experiencia del XXVI Ayuntamiento de Tepic (1972-1975), tesis de licenciatura en sociología, Guadalajara, mimeógrafo.

$\_$_ 1998, "Explorando los senderos del poder. El sistema político en el Nayarit contemporáneo”, en Lourdes Pacheco y Enedina Heredia (coords.), Nayarit al final del milenio, Universidad Autónoma de Nayarit, Tepic, México, pp. 283-316

Sánchez, Luis, 1996, "Dinámica del cacicazgo en Nayarit", en Autores varios, Régimen político y transición democrática en México, diplomado del mismo nombre, $\mathrm{Na}$ yarit, pp. 50-57

Wayne, Cornelius, 1972, "A Structural Analysis of Urban Caciquismo in Mexico", Urban Anthropology, núm. 1, vol. II, Massachusetts, pp. 234-261. 